\title{
Development of Noise Reduction Materials Based on Industry Residue of Power Plant
}

\author{
Teng Wang ${ }^{1, a}$, Junjun Geng ${ }^{1, b}$, Xin Zhang ${ }^{1, c}$, Jian Zeng ${ }^{1, d}$, Yongjie Xue $e^{2, e}$, \\ Gang Tan ${ }^{2, \mathrm{f}}$, Haobo Hou ${ }^{1, g}$, Min Zhou ${ }^{1, \mathrm{~h} *}$ \\ ${ }^{1}$ School of Resource and Environment Science, Wuhan University, Wuhan, China \\ ${ }^{2}$ State Key Laboratory of Silicate Materials for Architectures, Wuhan University of Technology, \\ Wuhan, China \\ a835473515@qq.com, bgengjj508@whu.edu.cn, 'zx9321@outlook.com, djarryzeng@hotmail.com, \\ exyjskl@whut.edu.cn, ${ }^{f}$ tg666happy@126.com, ${ }^{9} \mathrm{hhb}-$ bhh@163.com, ${ }^{\mathrm{h}}$ zhoumin@whu.edu.cn
}

Keywords: noise pollution, rice husk ash, non-autoclaved aerated material.

Abstract. Noise pollution issue has become a major problem in construction planning of High Voltage Direct Current (HVDC) transmission engineering. Meanwhile as the promotion of biomass power generation, rice husk ash (RHA) disposal problem has received widespread attention. This paper developed a new type of non-autoclaved aerated material using fly ash (FA) and RHA (after treatment) as main raw materials to act as noise reduction materials of capacitor. The results show that the material possesses excellent mechanical property, at the same time it has excellent noise performance.

\section{Introduction}

In recent years, Direct Current (DC) transmission technique has been developing rapidly with its advantage increasingly apparent in long distance transmission, grid connection, and flexible scheduling. With the improving of environmental awareness, environmental impact is going to be the key issue that must be taken into consideration of High Voltage (HV) DC transmission engineering. Beside that, noise pollution neglected in the past has become a major problem in construction planning of HVDC transmission engineering. Therefore the research in equipment noise of DC converter station is of great significance in ensuring the interests of people and guaranteeing the planning, construction and operation of DC transmission engineering $[1,2]$.

For the moment, DC converter station equipment mainly derived from noise generated by the capacitor. Capacitor noise reduction is a relatively feasible approach, it actualized by taking in or near the side of the fence wall on the nearby walls to reduce the noise barrier standing bounded noise. For capacitor towers twin towers arrangement, it is adopted by reducing the height of the capacitors to reduce the noise propagation distance. However, these measures will lead to higher cost and the noise reduction effect is not obvious. Aerated concrete, this unique structure has sound insulation effect, better than that of smooth, compact concrete and metal plate, it can improve plant especially the one with a high frequency sound $[3,6]$.

Biomass is one of the promising energy-carrying agents and plays an important role. Rice husk as one kind of biomass occupies a very important position in China due to the high production. As a fuel, rice husk is burned to generate energy, it also has byproduct, rice husk ash (RHA). If these 
RHA are not utilized, it will result in tremendous waste, energy loss and pollute environment. Therefore, how to utilize RHA comprehensively is a valuable research direction $[4,5]$.

This paper underlines the studies of the noise reduction performance of wall materials, including sound absorption coefficient and sound insulation quantity. The study of mechanical properties of wall materials is also necessary due to the extra layer with the need of wall materials bearing noise reduction layer. Waste residues from electric power industry, such as rice husk ash (RHA) and fly ash (FA) industrial, as the main materials, are used to produce non-autoclave aerated concrete. The production is used as the reduction noise material for capacitor, it can satisfy the demand for capacitor noise reduction, and reuse power plant waste residue at the same time. This method constructs the power system with the cycle of waste from the given process. Beside that, this paper also includes pretreatment of $\mathrm{R}$, discussion of chemical composition of raw materials, the change of crystallization degree and study of volcanic activity of raw materials.

\section{Materials}

This experiment use RHA from Sunshine kaidi biomass power plant as the row material. The color of ash is black and its density is $1789 \mathrm{~kg} / \mathrm{m}^{3}$. Majority of RHA is black ash, as RHA have burn in furnace when producing electricity. But the resident time of rice husk in the stove chamber is short, and the quantity of rice husk in the furnace is large, the situation leads to different degree of combustion of ash. A portion of the rice husk is not fully burned, so it is necessary to burn the RHA for the second time at $600 \square$ for $1 \mathrm{~h}$. In addition, particle sizes of RHA are different after burning. Parts of the ash can't satisfy the requirement of the specifications. According to the specifications, grinding of RHA is needed to achieve the standard of fineness. This paper chooses $30 \mathrm{~min}$ as the most appropriate grinding time. The main material composition analysis is shown in Table 1.

Table 1 Major chemical composition of raw materials

\begin{tabular}{ccccccccc}
\hline w/w $(\%)$ & $\mathrm{SiO}_{2}$ & $\mathrm{MgO}$ & $\mathrm{Fe}_{2} \mathrm{O}_{3}$ & $\mathrm{CaO}$ & $\mathrm{Al}_{2} \mathrm{O}_{3}$ & $\mathrm{~K}_{2} \mathrm{O}$ & $\mathrm{MnO}$ & $\mathrm{SO}_{3}$ \\
\hline RHA & 77.18 & 0.94 & 2.63 & 3.42 & 3.01 & 5.23 & 0.56 & 1.26 \\
$\mathrm{RHA}($ After treatment) & 89.03 & 0.54 & 1.02 & 3.81 & 0.71 & 1.26 & 0.39 & 0.36 \\
FA & 50.94 & 1.11 & 5.72 & 3.68 & 26.03 & & & \\
Cement & 23.1 & 2.18 & 3.67 & 57.59 & 7.1 & 0.72 & & 2.65 \\
Expanded perlite & 74.71 & 0.11 & 0.862 & 1.25 & 13.7 & 5.15 & & \\
\hline
\end{tabular}

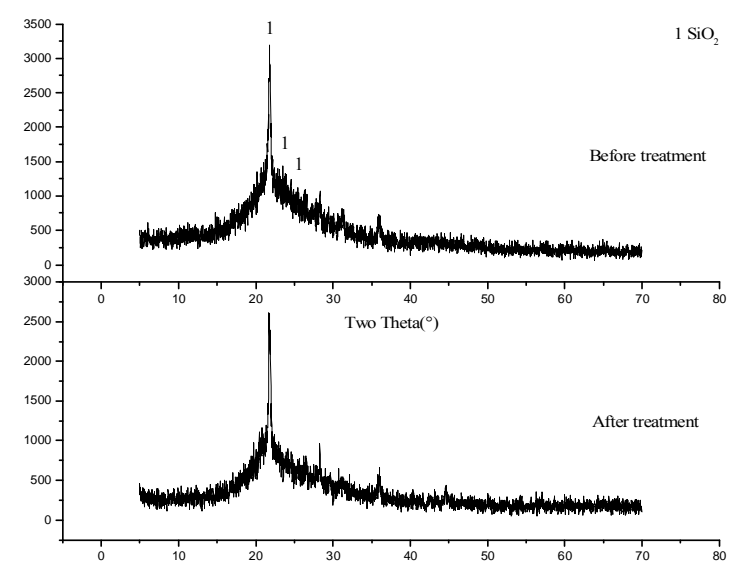

Fig 1 Comparison of RHA XRD patterns (before and after treatment)

After the secondary burning, chemical components of RHA are shown in Table 1. Table 1 indicates content of $\mathrm{SiO}_{2}$ in RHA increases significantly after burning, while others decline. The 
comparison of XRD patterns before and after treatment is shown in Fig 1. It shows that after treatment diffraction peak intensity of $\mathrm{SiO}_{2}$ is less than the untreated sample. Combined with chemical composition analysis, Fig 1 also indicates that the composition of amorphous $\mathrm{SiO}_{2}$ is higher after treatment.

Table 2 activity index of RHA (before and after treatment)

\begin{tabular}{cccc}
\hline \multirow{2}{*}{ Sample } & \multicolumn{3}{c}{ Activity index $/ \%$} \\
\cline { 2 - 4 } & $3 \mathrm{~d}$ & $7 \mathrm{~d}$ & $28 \mathrm{~d}$ \\
\hline RHA & 71.4 & 63.8 & 65.1 \\
\hline RHA(after treatment) & 95.8 & 97.7 & 96.1 \\
\hline
\end{tabular}

Table 2 shows activity index of RHA (before and after treatment) meet the requirement of the specifications to the activity index. Knowing from Table 2, the treated RHA demonstrates a higher pozzolanic activity, and it also shows the composition of amorphous $\mathrm{SiO}_{2}$ is higher after treatment.

\section{Results and discussion}

\section{Strength performance test}

Table 3 Raw material ratio

\begin{tabular}{|c|c|c|c|c|c|c|c|}
\hline No. & $\begin{array}{c}\text { Cement } \\
(\%)\end{array}$ & $\begin{array}{l}\text { FA } \\
(\%)\end{array}$ & $\begin{array}{l}\text { RHA } \\
(\%)\end{array}$ & $\begin{array}{l}\text { Expanded } \\
\text { perlite } \\
\quad(\%)\end{array}$ & $\begin{array}{c}\text { Activator } \\
(\%)\end{array}$ & $\begin{array}{c}\text { Lime } \\
(\%)\end{array}$ & $\begin{array}{l}\text { Gypsum } \\
(\%)\end{array}$ \\
\hline 1 & 12 & 50 & 20 & 1 & 4 & 10 & 3 \\
\hline 2 & 12 & 50 & 12 & 9 & 4 & 10 & 3 \\
\hline 3 & 12 & 50 & 16 & 5 & 4 & 10 & 3 \\
\hline 4 & 12 & 71 & 0 & 0 & 4 & 10 & 3 \\
\hline No. & $\mathrm{W} / \mathrm{C}$ & $\begin{array}{r}\text { All } \\
\text { pows } \\
\text { ingred }\end{array}$ & & \multicolumn{2}{|c|}{$\begin{array}{l}\text { Water reducing agent } \\
\text { (dry ingredients } \% \text { ) }\end{array}$} & \multicolumn{2}{|c|}{$\begin{array}{c}\text { Stable foam agent } \\
\text { (water reducing agent } \\
\% \text { ) }\end{array}$} \\
\hline 1 & 0.5 & \multicolumn{2}{|c|}{0.08} & \multicolumn{2}{|c|}{8.7} & \multicolumn{2}{|c|}{11.5} \\
\hline 2 & 0.5 & \multicolumn{2}{|c|}{0.08} & \multicolumn{2}{|c|}{8.7} & \multicolumn{2}{|c|}{11.5} \\
\hline 3 & 0.5 & \multicolumn{2}{|c|}{0.08} & \multicolumn{2}{|c|}{8.7} & \multicolumn{2}{|c|}{11.5} \\
\hline
\end{tabular}

According to the orthogonal test as had been done in the previous study, it's easy to determine the optimum mixture ratio as sample 4(blank sample). Detailed proportions of each material are shown in Table 3. Known from Fig 2, No.2 shows a greatest flexural strength than other samples at any curing time, while has a best compressive strength at 7 days and 14 days. But No.2 displays a less compressive strength at 28 days than No.1 and No.3. Their compressive performance is obviously better than blank sample, and their flexural properties are similar to blank sample. It illustrates that part replacement of FA by RAH (after treatment) and expanded perlite can improve the mechanical properties of aerated material, especially for their compressive performance. But when the pearlite content exceeds the limit, it will destroy the strength of materials. The result is caused by that expansion pearlite has a bigger specific surface area, so it is easy to join the pozzolanic reaction. Its excessive reactivity destroys uniformity of the porous structure, which affects the strength of products. 

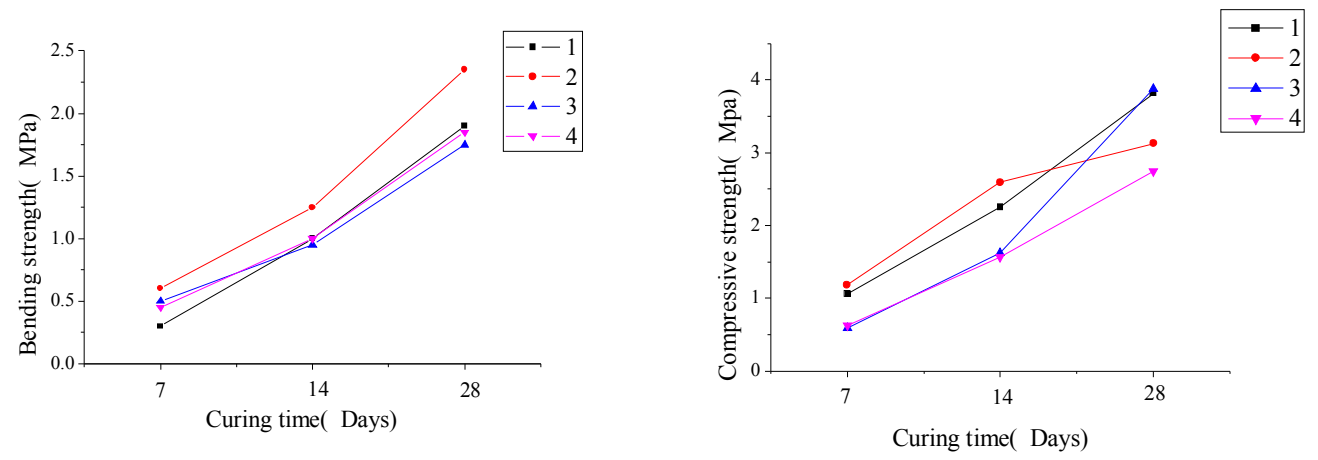

Fig 2 Flexural performance and compressive properties

Noise reduction performance test

Sound absorption performance

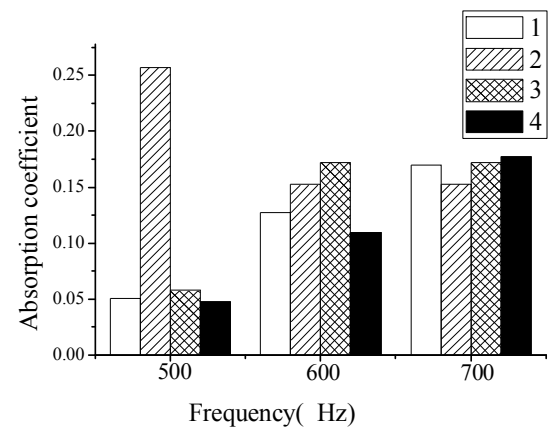

Fig 3 Sound absorption coefficient of capacitor under main noise frequency

Fig 3 shows that 2 has an outstanding performance at $500 \mathrm{~Hz}, 1,2,3$ have better sound absorption property under $600 \mathrm{~Hz}$. All of the samples have similar absorption at $700 \mathrm{~Hz}$. Comprehensive, 2 has the most excellent sound absorption performance under the main noise frequency. Compared with the common wall materials of sound absorption performance, aerated material has an obvious advantage.

Sound insulation performance

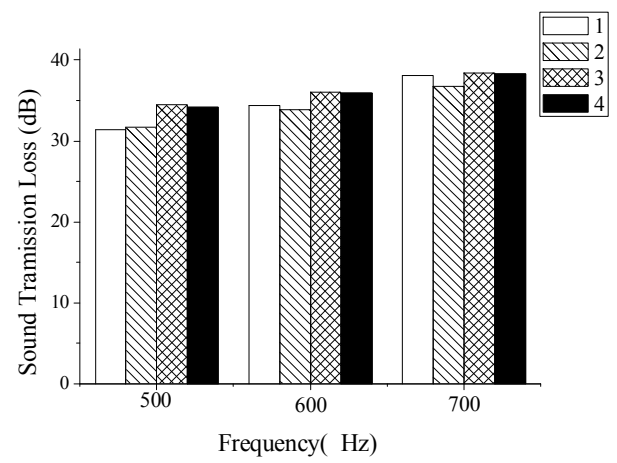

Fig 4 Sound insulation quantity of capacitor at main noise frequency

Learning from the Fig 4, under the main noise frequency of capacitor, four groups of products sound insulation performance have no significant difference. Sound insulation quantity of four products surpasses $30 \mathrm{db}$ at main noise frequency. It means that four groups of products show the superior sound insulation performance when thickness of board is less than the ordinary sound insulation board. 


\section{Conclusions}

In this paper, RHA must be treated by burning (at $600 \square$ for $1 \mathrm{~h}$ ) and grinding (for $30 \mathrm{~min}$ ) before use. Noise reduction materials of capacitor need certain mechanical property, meanwhile requires a certain amount of noise reduction performance. Considering mechanical properties and noise reduction performance of non-autoclaved aerated concrete block synthetically, the final ratio is established (cement: FA: RHA: perlite: lime: Gypsum=12:50:12:9:10:3). Products under the optimal ratio show excellent compressive and flexural strength. Simultaneously products possess obvious sound insulation effect, and the sound absorption coefficient is superior to conventional wall material. The material developed in this paper is suitable for noise debasing of capacitor.

\section{Acknowledgements}

This work is supported by Research on HVDC Filtering Equipment about the Mechanism of Noise Generation and Propagation Regularity with the Best Biomass Ash Aluminosilicate Based Porous Polymeric Noise Reduction Composites (2042014kf0233). The authors gratefully acknowledge their financial support.

\section{References}

[1] CIGRE technical report. HVDC stations audible noise[R]. No.202 W.G 14.26, France, 2002.

[2] Cox M D, Guan H H. Vibration and audible noise of capacitors subjected to non-sinusoidal waveforms[J].IEEE Transactions on Power Delivery, 1994, 9(2):856-862 .

[3] Mehta P K, Gjørv O E. Cement and Concrete Research, 1982, 12(5): 587-595.

[4] Givi A N, Rashid S A, Aziz F N A, et al.Construction and Building Materials, 2010, 24(11): 2145-2150.

[5] Nehdi M, Duquette J, El Damatty A.Cement and concrete research, 2003, 33(8): 1203-1210.

[6] Demirboğa R,Gül R. Cement and Concrete Research,2003,33(5): 723-727.

[7] Demirboğa R, Örüng İ, Gül R. Cement and Concrete Research, 2001, 31(11): 1627-1632.

[8] F .J .Molion, C. Alonso.. MaterialsandStructure, 2003, 26:532-548.

[9] Alexander son J. Cement, 1999:507 - 514.

[10] M.Kozak, L.Domka. Journal of Physics and Chemistry of Solids, 2010(65):441-445.

[11]N.Narayanan,K.Ramamurthy. Cement and Concrete Composites, 2000(22):321-329.

[12] Hu W.Y,Ronald, D.Neufeld. Journal of Energy Engineering, 1997(8):44-54. 